\title{
Proton magnetic resonance spectroscopy
} assessment of metabolite status of the anterior cingulate cortex in chronic pain patients and healthy controls

\author{
This article was published in the following Dove Press journal: \\ Journal of Pain Research \\ 31 January 2017 \\ Number of times this article has been viewed
}

\author{
Takahiro Ito' \\ Sachiko Tanaka-Mizuno ${ }^{2,3}$ \\ Narihito Iwashita ${ }^{4}$ \\ Ikuo Tooyama ${ }^{5}$ \\ Akihiko Shiino ${ }^{6}$ \\ Katsuyuki Miura ${ }^{1,7}$ \\ Sei Fukui ${ }^{4}$ \\ 'Department of Public Health, \\ Shiga University of Medical Science, \\ ${ }^{2}$ Department of Medical Statistics, \\ Shiga University of Medical Science, \\ Otsu, Japan; ${ }^{3}$ The Center for Data \\ Science Education and Research, \\ Shiga University, Hikone, Japan; \\ ${ }^{4}$ Department of Anesthesiology, \\ Interdisciplinary Pain Management \\ Center, Shiga University of Medical \\ Science Hospital, ${ }^{5}$ Molecular \\ Neuroscience Research Center, \\ Shiga University of Medical Science, \\ ${ }^{6}$ Biomedical MR Science Center, Shiga \\ University of Medical Science, ${ }^{7}$ Center \\ for Epidemiologic Research in Asia, \\ Shiga University of Medical Science, \\ Otsu, Japan
}

Correspondence: Sei Fukui Department of Anesthesiology, Interdisciplinary Pain Management Center, Shiga University of Medical Science Hospital, Seta Tsukinowa-cho, Otsu City, Shiga 520-2192, Japan

Tel +8I 77548228 I

Fax +8I 77548278 I

Email sei@belle.shiga-med.ac.jp
Background: Chronic pain is a common cause of reduced quality of life. Recent studies suggest that chronic pain patients have a different brain neurometabolic status to healthy people. Proton magnetic resonance spectroscopy $\left({ }^{1} \mathrm{H}-\mathrm{MRS}\right)$ can determine the concentrations of metabolites in a specific region of the brain without being invasive.

Patients and methods: We recruited 56 chronic pain patients and 60 healthy controls to compare brain metabolic characteristics. The concentrations of glutamic acid (Glu), myo-inositol (Ins), $N$-acetylaspartate (NAA), Glu + glutamine (Glx), and creatine + phosphocreatine (total creatine $[\mathrm{tCr}])$ in the anterior cingulate cortex of participants were measured using ${ }^{1} \mathrm{H}-\mathrm{MRS}$. We used age- and gender-adjusted general linear models and receiver-operating characteristic analyses for this investigation. Patients were also assessed using the Hospital Anxiety and Depression Scale (HADS) to reveal the existence of any mental health issues.

Results: Our analysis indicates that pain patients have statistically significantly higher levels of Glu/ $\operatorname{tCr}(p=0.039)$ and $\mathrm{Glx} / \mathrm{tCr}(p<0.001)$ and lower levels of NAA/tCr than controls, although this did not reach statistical significance $(p=0.052$ ). Receiver-operating characteristic analysis performed on the combination of $\mathrm{Glx} / \mathrm{tCr}$, Ins/tCr, and NAA/tCr effectively discriminated chronic pain patients from healthy controls. Patients with higher HADS-Depression scores had increased Glx/rCr levels ( $p=0.015$ ), and those with higher HADS-Anxiety scores had increased NAA/tCr levels $(p=0.018)$. Conclusion: Chronic pain patients have a different metabolite status in the anterior cingulate cortex to controls. Within the pain patient group, HADS scores had a positive relationship with $\mathrm{NAA} / \mathrm{tCr}$ and $\mathrm{Glx} / \mathrm{tCr}$ levels. ${ }^{1} \mathrm{H}-\mathrm{MRS}$ successfully detected metabolic changes in patients' brains in a noninvasive manner, revealing its potential as a superior diagnostic tool for pain patients. Keywords: chronic pain, magnetic resonance spectroscopy, glutamic acid, myo-inositol, $N$-acetylaspartate, creatine

\section{Introduction}

Chronic pain is a common cause of reduced quality of life. ${ }^{1,2}$ There are many therapies available for patients with chronic pain, but these are not always effective. ${ }^{3}$ Neuropathy is one of the major causes of chronic pain, ${ }^{4}$ with the pain often continuing for a long time despite the recovery from the original injury or inflammation due to nerve degeneration. ${ }^{5}$ There has been an increase in the numbers of neuropathic pain patients, particularly in the elderly. ${ }^{6}$ Chronic pain has become not only an individual burden but also a serious social problem owing to increasing medical care expenses and the deterioration of quality of life. ${ }^{2}$ 
Health professionals now believe that the treatment of pain requires attention to psychological issues, as they have a causal influence on pain. ${ }^{1}$ Some studies indicate that pain signals and psychological information are integrated in the anterior cingulate cortex (ACC) ${ }^{7,8}$ Other studies indicate that chronic pain patients have a different brain neurometabolic status to healthy persons. ${ }^{1,9}$ Computed tomography or magnetic resonance imaging (MRI) cannot detect such differences. Positron emission tomography can detect metabolic activity in brain but requires the invasive injection of a radioactive tracer. However, proton magnetic resonance spectroscopy ( $\left.{ }^{1} \mathrm{H}-\mathrm{MRS}\right)$ can evaluate the concentration of metabolites in specific brain regions without being invasive. ${ }^{10}$ While past MRS studies have reported several findings associated with pain syndromes, more research is required before we can conclude that MRS has diagnostic value. ${ }^{9}$ Moreover, the study about relationship between pain and mood disorder is scarce, especially in Asia.

In this study, we conducted a cross-sectional study to evaluate the level of metabolites in the ACC of chronic pain patients and healthy controls using ${ }^{1} \mathrm{H}-\mathrm{MRS}$. Our primary objective was to compare the metabolic status of chronic pain patients and controls. The secondary objective was to study the relationship between metabolites and the ratings of depression and anxiety in chronic pain patients.

\section{Materials and methods Study design}

This study was a cross-sectional study conducted at the Shiga University of Medical Science Hospital in Otsu, Japan. Cases with an element of chronic pain were recruited from patients of the Interdisciplinary Pain Treatment Center in the hospital from June 2012 to May 2016. Healthy controls without any persistent pain, current disease, or medical history of brain impairment were recruited from hospital staff and their relatives, and students. The study protocol was approved by the Ethics Committee at the Shiga University of Medical Science. All participants provided signed informed consent forms when joining this study.

Chronic pain was assessed by a pain physician at the Interdisciplinary Pain Treatment Center. In this study, the criteria for neuropathic pain included chronic pain caused by neurological damage (narrowing of the spinal canal, trigeminal neuralgia, intercostal neuralgia, postoperative neuropathy, radiculopathy, plexus injury, peripheral neuro injury, reflex sympathetic dystrophy, and diabetic neuropathy). The other cases of chronic pain that were not considered neuropathic pain were fibromyalgia, cephalalgia, somatoform disorder, and unidentified general or partial pain. All patients had been treated at another hospital before, but did not show any improvement of their pain symptoms, so then started multimodality therapy at the Interdisciplinary Pain Treatment Center.

\section{Magnetic resonance spectroscopy}

All MRI scans were performed at the Shiga University of Medical Science. A 3-tesla (3T)-MRI equipped device for MRS (Signa Horizon NL; General Electric Co., Milwaukee, WI, USA) was used. By referring to a T1-weighted image, the voxel region $(2 \times 2 \times 4 \mathrm{~cm}$ cuboid) for measuring the proton metabolite data was set in the ACC area as the volume of interest (VOI; Figure 1A). The conditions of this MRS examination were: echo time (TE), $30 \mathrm{~ms}$; repetition time (TR), 2,000 ms; and number of averages (NS), 96. We ascertained the absolute concentration of each metabolite using LCModel analytic software ${ }^{11}$ (Figure 1B).

\section{Measurements}

We measured the concentration of glutamic acid (Glu), myoinositol (Ins), $N$-acetylaspartate (NAA), Glu + glutamine (Gln) (Glx), and creatine + phosphocreatine ( $\mathrm{tCr}$ ) in the ACC. Metabolite levels are currently often expressed as ratios, as these are more capable of detecting changes in metabolites, and thus are more accurate than absolute concentrations. ${ }^{12}$ Therefore, we used the ratios of metabolite concentration divided by $\mathrm{tCr}$ concentration in this study.

Gender and age data were collected from all participants. Details of the disease duration, site of pain, presence or absence of neuropathic pain, and treatment were collected from chronic pain patients. The patients completed the HADS to enable analysis of their emotional status living with chronic pain. ${ }^{13}$

\section{Statistical analysis}

The baseline characteristics of cases and controls were described. Median values with interquartile ranges and percentages were used to describe age, gender, and patients' characteristics including duration of disease, site of pain, presence or absence of neuropathic pain, treatment, and medication.

Linear regression models adjusted for age and gender were used to compare the mean metabolite levels $(\mathrm{Glu} / \mathrm{tCr}$, $\mathrm{Glx} / \mathrm{tCr}$, Ins/tCr, and $\mathrm{NAA} / \mathrm{tCr}$ ) between chronic pain patients and controls. The differences in means between chronic pain patients and controls were estimated after adjustment for age and gender, and $p$-values were assessed with respect to the four defined metabolites. To evaluate the heterogeneity of the types of chronic pain, we also conducted a subgroup analysis, stratified by neuropathic pain and back pain. Consistency in the levels of each metabolite between subgroups defined by the presence of neuropathic pain and the site of the pain was evaluated by adding interaction terms to the statistical models. 
A
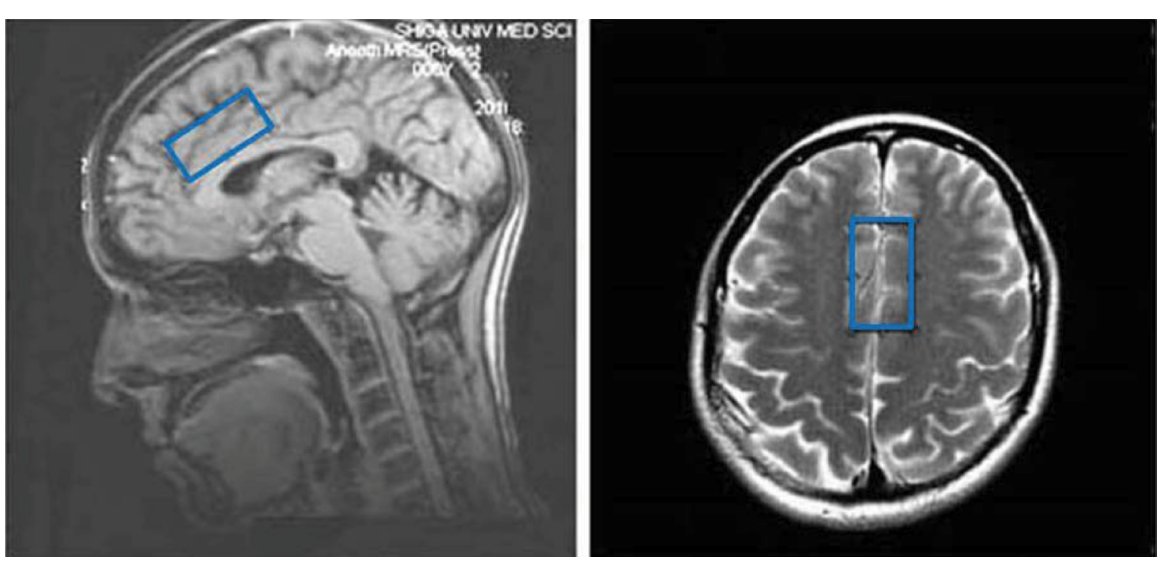

B

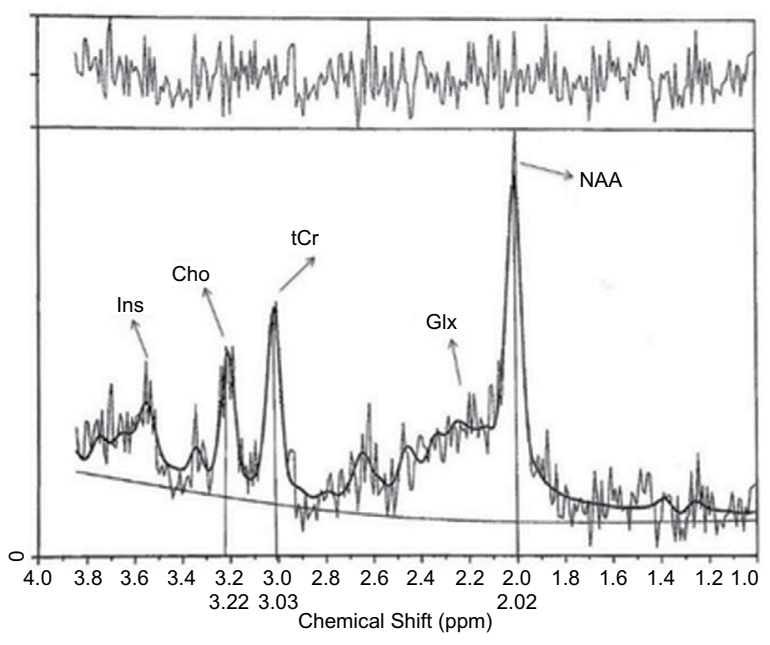

Control

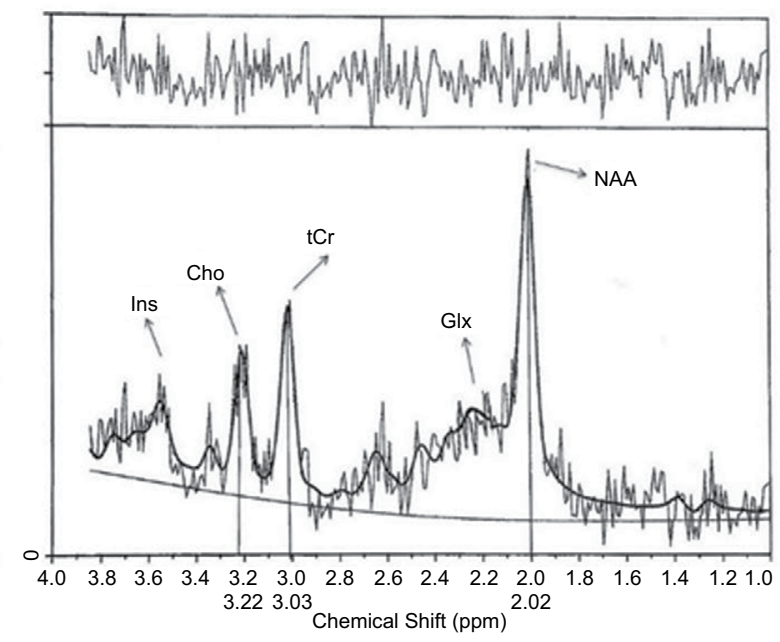

Chronic pain patient

Figure I (A) The blue rectangle shows the location of a single voxel in the anterior cingulate cortex. (B) Representative proton magnetic resonance spectroscopy spectrum from the anterior cingulate cortex fit with LCModel.

Abbreviations: Ins, myo-inositol; Cho, choline; tCr, creatine + phosphocreatine; Glx, glutamic acid + glutamine; NAA, N-acetylaspartate.

Multivariable logistic regression models were used to estimate the odds ratio (OR) of continuous metabolite levels comparing chronic pain patients with controls. The metabolite levels were divided by 10 , and the ORs were interpreted as a decreased or increased risk per change of 0.1 unit for all metabolites. We also conducted receiver-operating characteristic (ROC) analysis and estimated the C-index to evaluate the discrimination performance of each metabolite. The model that best discriminates chronic pain patients from healthy controls has a higher C-index value. Statistical hypothesis testing was also conducted to evaluate the difference between the C-index of each model and the base model, which only includes age and gender.

To evaluate the relationship between patient-oriented scores, such as psychophysical measures, and metabolite levels in chronic pain patients, multiple linear regression analysis, which includes patients' scores from HADS-Anxiety or HADS-Depression for responsible variables, and age and gender as adjustment variables, was performed. To assess risk factors, we divided the chronic pain patients into three groups by tertiles of metabolite levels and compared the group means. The tertiles were as follows: $\mathrm{Glu} / \mathrm{tCr}:<1.32,1.32-1.47$, $>1.47$; Glx/tCr: <1.83, 1.83-2.10, >2.10; Ins/tCr: <0.84, $0.84-0.91,>0.91$; and NAA/tCr: $<1.14,1.14-1.25,>1.25$. We then compared the differences in HADS scores between the three groups. The adjusted mean of patients' score levels in the three groups were estimated and the differences between groups evaluated using Dunnett's test, which compared the lowest tertile group to the other two groups and the trend test, which evaluate the trend tendency of four groups.

All statistical analyses were conducted using SAS 9.4 software (SAS Institute, Cary, NC, USA).

\section{Results}

Fifty-six chronic pain patients and 60 normal healthy subjects, all of whom were Japanese, participated in this study. 
Table 1 shows the baseline characteristics of participants. In the chronic pain and control groups, the median ages were 58 and 40 years, respectively, and the percentages of men were $32.1 \%$ and $36.7 \%$, respectively. In the chronic pain patient group, the median chronic pain duration was 36.5 months, and $68.6 \%$ suffered from neuropathic pain, while $53.6 \%$ presented with back pain.

The means and standard deviations (SDs) of the neurometabolic levels for chronic pain patients and controls as well as the results from linear regression models comparing the metabolite levels between the two populations are shown in Table 2. The average (SD) signal-to-noise ratio $(\mathrm{S} / \mathrm{N})$ of the spectra was 29.3 (9.3), and the average full width at half maximum was $0.041(0.990)$ ppm. To check the stability of $\mathrm{tCr}$ level between subgroups, we conducted Student's $t$-test to compare each mean $\mathrm{tCr}$ divided by the presence of neuropathic pain or site of pain. There were no significant differences of mean $\mathrm{tCr}$ between subgroups (presence of neuropathic pain or not $[p=0.833]$, back pain or the other pain $[p=0.703])$. Compared with the control group, the mean $\mathrm{Glu} / \mathrm{tCr}$ and $\mathrm{Glx} / \mathrm{tCr}$ was higher in the patient group (adjusted mean difference $[95 \%$ confidence intervals $\{\mathrm{CIs}\}]$; $\mathrm{Glu} / \mathrm{tCr}$ 0.063 [0.003, 0.123], $p=0.039 ; \mathrm{Glx} / \mathrm{tCr} 0.206$ [0.104, 0.308], $p<0.001)$. The mean NAA/tCr was lower in the patient group compared with the control group (adjusted mean difference $[95 \% \mathrm{CI}] ;-0.042[-0.084,0.000], p=0.052)$. The difference

Table I Baseline characteristics of the study participants

\begin{tabular}{|c|c|c|}
\hline & $\begin{array}{l}\text { Chronic pain } \\
\text { patients, } N=56\end{array}$ & $\begin{array}{l}\text { Controls, } \\
\mathrm{N}=60\end{array}$ \\
\hline Age (years) & $58(45-67)$ & $40(28-48)$ \\
\hline \multicolumn{3}{|l|}{ Gender (\%) } \\
\hline Male & 32.1 & 36.7 \\
\hline Female & 67.9 & 63.3 \\
\hline $\begin{array}{l}\text { Duration of disease } \\
\text { (months) }\end{array}$ & $36.5(\mid 3.5-74.5)$ & - \\
\hline \multicolumn{3}{|l|}{ Treatment for pain (\%) } \\
\hline No treatment & 8.90 & - \\
\hline Only NSAIDs & 21.40 & - \\
\hline NSAIDs and other pain drugs & 57.10 & - \\
\hline Nerve block and others & 12.50 & - \\
\hline \multicolumn{3}{|c|}{ Presence of neuropathic pain (\%) } \\
\hline Yes & 78.6 & - \\
\hline No & 21.4 & - \\
\hline \multicolumn{3}{|l|}{ Site of pain (\%) } \\
\hline Back & 53.6 & - \\
\hline Other site & 46.4 & - \\
\hline \multicolumn{3}{|c|}{ Questionnaire (pain patients only) } \\
\hline HADS-Anxiety & $9(7-12)$ & - \\
\hline HADS-Depression & $10(5-12)$ & - \\
\hline
\end{tabular}

Note: All data are reported as medians with IQR or percentages.

Abbreviations: HADS, Hospital Anxiety and Depression Scale; IQR, interquartile range; NSAIDs, non-steroidal anti-inflammatory drugs.
Table 2 Comparison of neurometabolite levels in the ACC between chronic pain patients and controls

\begin{tabular}{lllll}
\hline & $\begin{array}{l}\text { Pain } \\
\text { patients, } \\
\mathbf{N}=\mathbf{5 6}\end{array}$ & $\begin{array}{l}\text { Controls, } \\
\mathbf{N}=\mathbf{6 0}\end{array}$ & $\begin{array}{l}\text { Adjusted mean } \\
\text { difference } \\
(\mathbf{9 5 \%} \mathbf{C l})\end{array}$ & p-value \\
\hline $\mathrm{Glu} / \mathrm{tCr}$ & $\mathrm{I} .425(0.155)$ & $\mathrm{I} .400(0.128)$ & $\begin{array}{l}0.063 \\
(0.003,0.123)\end{array}$ & 0.039 \\
$\mathrm{Gl} / \mathrm{tCr}$ & $2.021(0.290)$ & $\mathrm{I} .857(0.180)$ & $\begin{array}{l}0.206 \\
(0.104,0.308)\end{array}$ & $<0.001$ \\
$\mathrm{Ins} / \mathrm{tCr}$ & $0.887(0.104)$ & $0.900(0.086)$ & $\begin{array}{l}-0.018 \\
(-0.059,0.023)\end{array}$ & $0.38 \mathrm{I}$ \\
$\mathrm{NAA} / \mathrm{tCr}$ & $1.207(0.100)$ & $1.273(0.099)$ & $\begin{array}{l}-0.042 \\
(-0.084,0.000)\end{array}$ & 0.052 \\
\hline
\end{tabular}

Notes: All data were summarized as mean (SDs). Adjusted mean differences and $p$-values were calculated using linear regression models including gender and age as adjustment variables.

Abbreviations: $\mathrm{Cl}$, confidence interval; Glu, glutamic acid; Glx, glutamic acid + glutamine; Ins, myo-inositol; NAA, N-acetylaspartate; SD, standard deviation; tCr, creatine + phosphocreatine.

in Ins/tCr was not significant ( $p=0.381$ ). In subgroup analysis, there was no heterogeneity between subgroup defined by the presence of neuropathic pain and the site of the pain (all $p$-values for heterogeneity $>0.10$ ).

After adjusting for age and gender, there was a significantly increased association of chronic pain and $\mathrm{Glu} / \mathrm{tCr}$ and Glx/tCr levels (Table 3). Conversely, there was the tendency of a decreased association for NAA/tCr. The ROC analysis revealed that a combination of $\mathrm{NAA} / \mathrm{tCr}, \mathrm{Glx} / \mathrm{tCr}$, and $\mathrm{Ins} / \mathrm{tCr}$ had a higher $\mathrm{C}$-index than the combination of $\mathrm{NAA} / \mathrm{tCr}, \mathrm{Glu} /$ $\mathrm{tCr}$, and $\mathrm{Ins} / \mathrm{tCr}$. Compared with the models including a single metabolite ( $\mathrm{Glu} / \mathrm{tCr}$, for Model 1; Glx/tCr, for Model 2; Ins/tCr, for Model 3; NAA/tCr, for Model 4), the models including three metabolites $(\mathrm{Glu} / \mathrm{tCr}$, Ins/tCr, and NAA/tCr, for Models 5; Glx/ $\mathrm{tCr}$, Ins $/ \mathrm{tCr}$, and NAA/tCr, for Model 6) had the higher C-index.

Figure 2 shows the results of general linear models analysis, adjusted by age and gender, to evaluate the association between HADS score and metabolite levels in chronic pain patients only. The mean HADS-Anxiety score in the highest $\mathrm{NAA} / \mathrm{tCr}$ group was significantly higher than in the lowest $\mathrm{NAA} / \mathrm{tCr}$ group $(p=0.019)$, and there was a positive relationship between HADS-Anxiety score and the ordinal categorical groups of NAA/tCr ( $p$-value of trend test; $p=0.018$ ). The mean HADS-Depression score in the highest $\mathrm{Glx} / \mathrm{tCr}$ group was significantly higher than in the lowest $\mathrm{Glx} / \mathrm{tCr}$ group ( $p=0.018)$, and there was a positive relationship between HADS-Depression score and the ordinal categorical groups of Glx/tCr ( $p$-value of trend test; 0.015).

\section{Discussion}

This cross-sectional study was carried out to evaluate the differences in brain metabolic levels between 56 chronic 
Table 3 Results from gender- and age-adjusted logistic regression to evaluate the discrimination performance of metabolite levels

\begin{tabular}{|c|c|c|c|c|c|}
\hline \multirow[t]{2}{*}{ Model $^{a}$} & & \multicolumn{2}{|c|}{$\begin{array}{l}\text { Odds ratio (OR) per } \\
0.1 \text {-unit metabolite } \\
\text { level }^{\mathrm{b}}\end{array}$} & \multicolumn{2}{|c|}{ ROC analysis } \\
\hline & & OR (95\% Cl) & $p$-value & C-index & $p$-value ${ }^{c}$ \\
\hline Model I & $\mathrm{Glu} / \mathrm{tCr}$ & $\begin{array}{l}1.415(1.024 \\
1.955)\end{array}$ & 0.036 & 0.812 & 0.364 \\
\hline Model 2 & $\mathrm{Gl} / \mathrm{tCr}$ & $\begin{array}{l}1.463(1.182 \\
1.811)\end{array}$ & 0.001 & 0.847 & 0.060 \\
\hline Model 3 & $\mathrm{Ins} / \mathrm{tCr}$ & $\begin{array}{l}0.821(0.524 \\
\text { I.288) }\end{array}$ & 0.391 & 0.796 & 0.957 \\
\hline Model 4 & $\mathrm{NAA} / \mathrm{tCr}$ & $\begin{array}{l}0.651(0.413 \\
1.028)\end{array}$ & 0.066 & 0.809 & 0.454 \\
\hline \multirow[t]{3}{*}{ Model 5} & $\mathrm{Glu} / \mathrm{tCr}$ & $\begin{array}{l}1.597(1.098 \\
2.324)\end{array}$ & 0.014 & 0.843 & 0.058 \\
\hline & $\mathrm{NAA} / \mathrm{tCr}$ & $\begin{array}{l}0.605(0.374 \\
0.978)\end{array}$ & 0.040 & & \\
\hline & $\mathrm{Ins} / \mathrm{tCr}$ & $\begin{array}{l}0.805(0.497 \\
1.304)\end{array}$ & 0.378 & & \\
\hline \multirow[t]{3}{*}{ Model 6} & $\mathrm{Glx} / \mathrm{tCr}$ & $\begin{array}{l}1.600(1.253 \\
2.044)\end{array}$ & 0.001 & 0.866 & 0.020 \\
\hline & $\mathrm{NAA} / \mathrm{tCr}$ & $\begin{array}{l}0.583(0.348 \\
0.976)\end{array}$ & 0.040 & & \\
\hline & Ins/tCr & $\begin{array}{l}0.690(0.910 \\
1.020)\end{array}$ & 0.186 & & \\
\hline
\end{tabular}

Notes: aAll models include age and gender as adjusted variables. In addition to age and gender, Models I-4 include a single metabolite level and Models 5 and 6 include three metabolite levels. 'bogistic regression models estimate the odds ratios per unit for each metabolite. 'Statistical hypothesis test was conducted to evaluate the difference between C-indexes of each model and the base model, which only includes age and gender. Abbreviations: Glu, glutamic acid; Glx, glutamic acid + glutamine; Ins, myo-inositol; NAA, $\mathrm{N}$-acetylaspartate; ROC, receiver-operating characteristic; $\mathrm{tCr}$, creatine + phosphocreatine.

pain patients and 60 controls. There has been little research into the roles of neurometabolites in pain patients, and less has been done in Asia than in the United States and Europe. This study of the relationship between neurometabolites and chronic pain is one of the few that have occurred in Asia. However, to further these results, more studies with larger samples and other psychological evaluations are needed.

The comparisons between the chronic pain patients and controls showed significantly higher $\mathrm{Glu} / \mathrm{tCr}$ and $\mathrm{Glx} / \mathrm{tCr}$ levels in the chronic pain patients. Similarly, NAA/tCr was lower in the chronic pain patients compared with controls although this did not reach statistical significance. ${ }^{14}$ These results are similar to those of previous studies. ${ }^{9}{ }^{15-18}$ It is thought that the elevation of Glu and Gln is caused by accentuation of the Glu/ Gln cycle in response to pain. ${ }^{15}$ Also, astrocyte activation by chronic pain could reduce Glu reuptake. ${ }^{14,19}$ A previous report suggested that the excess of Glu neurotransmission could lead to neuronal damage, and that could then decrease NAA in chronic pain patients. ${ }^{15}$ Ins is thought of as a glial marker and elevated levels caused by chronic pain have frequently been reported. ${ }^{1,9}$ Conversely, there has been a report indicating no difference in brain Ins levels in pain patients and controls. ${ }^{16}$ Our study indicates that $\mathrm{Ins} / \mathrm{tCr}$ is statistically unrelated to a person being a pain patient. The discrepancies between these findings may be attributable to differences in the study designs, the characteristics of the participants, the species investigated, the magnetic field strength, and the underlying cause of pain.

A previous study attributed the modulation of emotional responses to the ACC. ${ }^{20}$ Consequently, changes in metabolites in the ACC may have effects on psychological measurement values. In our study, there was a significant positive correlation between HADS-Depression and Glx/tCr, and HADS-Anxiety and $\mathrm{NAA} / \mathrm{tCr}$ in the chronic pain patients. The nature of the interaction between depression, anxiety, and metabolites has no established theory yet, although numerous studies have published related findings. ${ }^{17,21-24}$ We believe that our findings here may contribute to elucidating that mechanism.

As pain is an essentially subjective experience, technology like MRS is useful for providing objective information. The use of MRS for diagnosis is anticipated. ${ }^{25-29}$ Here, we have shown that the ability to separate healthy controls and pain patients was improved by the multiple ROC approach. Combining the information of the three metabolites, Glx/ $\mathrm{tCr}$, Ins $/ \mathrm{tCr}$, and $\mathrm{NAA} / \mathrm{tCr}$, was superior to using each value alone. There are no similar reports describing this approach to pain patients that we know of.

This study was cross-sectional, so we cannot determine if the pain precedes the change of metabolites or not. However, previous research has indicated that metabolites in the brain could be a target for pain treatment. ${ }^{30}$ MRS may be useful for measuring the effectiveness of treatment in the near future. Therefore, metabolite data gathering as in this study are even more important in order to choose the best treatment for pain patients.

Recently, the magnetic field used in ${ }^{1} \mathrm{H}-\mathrm{MRS}$ has shifted from $1.5 \mathrm{~T}$ magnetic field to $3 \mathrm{~T}$ for a better $\mathrm{S} / \mathrm{N}$ ratio in $3 \mathrm{~T}$. According to previous research, the $\mathrm{S} / \mathrm{N}$ ratio does not increase substantially above $3 \mathrm{~T}^{31} \mathrm{~A}$ former Japanese report investigating the relationship between chronic pain and metabolites was conducted using 1.5 T MRS. ${ }^{18}$ Our MRS data were measured in $3 \mathrm{~T}$, making it more sensitive than the previous 1.5 T MRS data.

This study has several limitations. We did not evaluate a change in the metabolites in any brain region other than the ACC. It is possible that changes in metabolite levels in other brain regions might affect the patient's perception and mental status. We could not adjust for the influence of medical treatment because the variety of treatments in each patient was very complicated. Similarly, we did not use disease duration as an adjustment variable, which may also affect the results of this study. It is also possible that due to differences 

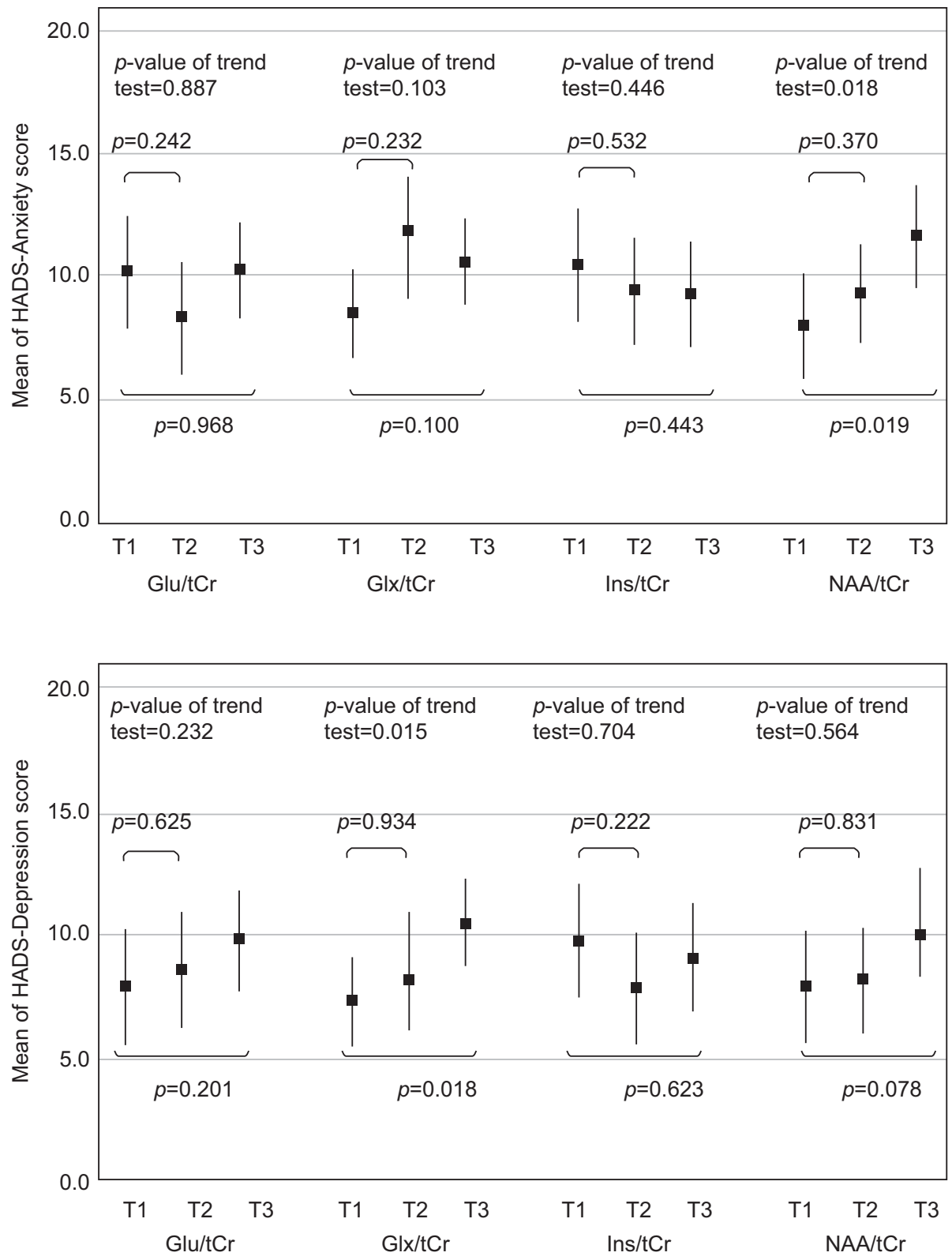

Figure 2 Relationship between HADS-Anxiety and -Depression scores and neurometabolite levels.

Notes: Age- and gender-adjusted mean values (closed square) and $95 \%$ confidence intervals (error bar) were described by the tertiles of metabolite levels. TI, T2, and T3 show the group of metabolite levels divided by 33.3 and 66.7 percentiles. $p$-values that are calculated by the Dunnett's test and trend test are also shown.

Abbreviations: Glu, glutamic acid; Glx, glutamic acid + glutamine; HADS, Hospital Anxiety and Depression Scale; Ins, myo-inositol; NAA, N-acetylaspartate; tCr, creatine + phosphocreatine.

in individual brain sizes, VOI settings may not have been precise, but that could be normalized using the $\mathrm{tCr}$ ratio.

\section{Conclusion}

Our results revealed that in chronic pain patients, the mean levels of $\mathrm{Glu} / \mathrm{tCr}$ and $\mathrm{Glx} / \mathrm{tCr}$ are higher, but lower for NAA/ $\mathrm{tCr}$, compared with healthy controls.

ROC analysis suggests that the models including several metabolic levels with a higher $\mathrm{C}$-index more easily discriminate chronic pain patients from healthy controls. We also found a positive correlation between HADS-Depression and Glx/
$\mathrm{tCr}$, and HADS-Anxiety and NAA/tCr. MRS is a noninvasive measurement device for metabolites in the brain and could be useful for determining the best treatments for pain patients.

\section{Acknowledgments}

We thank Masahiro Yoshimura and Katsunori Miyata, radiological technologists of the Department of Radiology, Shiga University of Medical Science Hospital for the MRI data management. This study was funded by a Grant-in-Aid for Scientific Research (C) from the Japanese Ministry of Health, Labour and Welfare (grant number 23592284). 


\section{Disclosure}

The authors report no conflicts of interest in this work.

\section{References}

1. Widerstrom-Noga E, Pattany PM, Cruz-Almeida Y, Felix ER, Perez S, Cardenas DD, Martinez-Arizala A. Metabolite concentrations in the anterior cingulate cortex predict high neuropathic pain impact after spinal cord injury. Pain. 2013;154(2):204-212.

2. Phillips CJ. The cost and burden of chronic pain. Rev Pain. 2009;3(1):2-5.

3. Watson CP, Evans RJ. A comparative trial of amitriptyline and zimelidine in post-herpetic neuralgia. Pain. 1985;23(4):387-394.

4. Peyron R. [Pathophysiology of chronic pain. Classification of three subtypes of pain]. Rev Prat. 2013;63(6):773-778. French.

5. Woolf CJ, Mannion RJ. Neuropathic pain: aetiology, symptoms, mechanisms, and management. Lancet. 1999;353(9168):1959-1964.

6. Rapo-Pylkko S, Haanpaa M, Liira H. Neuropathic pain among community-dwelling older people: a clinical study in Finland. Drugs Aging. 2015;32(9):737-742.

7. Barthas F, Sellmeijer J, Hugel S, Waltisperger E, Barrot M, Yalcin I. The anterior cingulate cortex is a critical hub for pain-induced depression. Biol Psychiatry. 2015;77(3):236-245.

8. Apkarian AV, Bushnell MC, Treede RD, Zubieta JK. Human brain mechanisms of pain perception and regulation in health and disease. Eur J Pain. 2005;9(4):463-484.

9. Chang L, Munsaka SM, Kraft-Terry S, Ernst T. Magnetic resonance spectroscopy to assess neuroinflammation and neuropathic pain. J Neuroimmune Pharmacol. 2013;8(3):576-593.

10. Grachev ID, Fredrickson BE, Apkarian AV. Abnormal brain chemistry in chronic back pain: an in vivo proton magnetic resonance spectroscopy study. Pain. 2000;89(1):7-18.

11. Helms G. Analysis of 1.5 Tesla proton MR spectra of human brain using LC Model and an imported basis set. Magn Reson Imaging. 1999; 17(8):1211-1218.

12. Jansen JF, Backes WH, Nicolay K, Kooi ME. 1H MR spectroscopy of the brain: absolute quantification of metabolites. Radiology. 2006;240(2):318-332.

13. Zigmond AS, Snaith RP. The hospital anxiety and depression scale. Acta Psychiatr Scand. 1983;67(6):361-370.

14. Kettenmann H, Kirchhoff F, Verkhratsky A. Microglia: new roles for the synaptic stripper. Neuron. 2013;77(1):10-18.

15. Mullins PG, Rowland LM, Jung RE, Sibbitt WL Jr. A novel technique to study the brain's response to pain: proton magnetic resonance spectroscopy. Neuroimage. 2005;26(2):642-646.

16. Gussew A, Rzanny R, Gullmar D, Scholle HC, Reichenbach JR. 1H-MR spectroscopic detection of metabolic changes in pain processing brain regions in the presence of non-specific chronic low back pain. Neuroimage. 2011;54(2):1315-1323.
17. Mahmutyazicioglu K, Konuk N, Ozdemir H, Atasoy N, Atik L, Gundogdu S. Evaluation of the hippocampus and the anterior cingulate gyrus by proton MR spectroscopy in patients with post-traumatic stress disorder. Diagn Interv Radiol. 2005;11(3):125-129.

18. Fukui S, Matsuno M, Inubushi T, Nosaka S. N-Acetylaspartate concentrations in the thalami of neuropathic pain patients and healthy comparison subjects measured with ${ }^{1} \mathrm{H}-\mathrm{MRS}$. Magn Reson Imaging. 2006;24(1):75-79.

19. Nakagawa T, Otsubo $Y$, Yatani $Y$, Shirakawa H, Kaneko S. Mechanisms of substrate transport-induced clustering of a glial glutamate transporter GLT-1 in astroglial-neuronal cultures. Eur J Neurosci. 2008;28(9):1719-1730.

20. Bush G, Luu P, Posner MI. Cognitive and emotional influences in anterior cingulate cortex. Trends Cogn Sci. 2000;4(6):215-222.

21. Marazziti D, Abelli M, Baroni S, Carpita B, Piccinni A, Dell L. Recent findings on the pathophysiology of social anxiety disorder. Clin Neuropsychiat. 2014;11(2):91-100.

22. Sanacora G, Gueorguieva R, Epperson CN, et al. Subtype-specific alterations of gamma-aminobutyric acid and glutamate in patients with major depression. Arch Gen Psychiatry. 2004;61(7):705-713.

23. Hasler G, van der Veen JW, Tumonis T, Meyers N, Shen J, Drevets WC. Reduced prefrontal glutamate/glutamine and gamma-aminobutyric acid levels in major depression determined using proton magnetic resonance spectroscopy. Arch Gen Psychiatry. 2007;64(2):193-200.

24. Moon CM, Jeong GW. Brain morphological alterations and cellular metabolic changes in patients with generalized anxiety disorder: a combined DARTEL-based VBM and ${ }^{1} \mathrm{H}-\mathrm{MRS}$ study. Magn Reson Imaging. 2016;34(4):429-436.

25. Aguila ME, Lagopoulos J, Leaver AM, Rebbeck T, Hübscher M, Brennan PC, Refshauge KM. Elevated levels of GABA+ in migraine detected using ${ }^{1}$ H-MRS. NMR Biomed. 2015;28(7):890-897.

26. Shonk TK, Moats RA, Gifford P, Michaelis T, Mandigo JC, Izumi J, Ross BD. Probable Alzheimer disease: diagnosis with proton MR spectroscopy. Radiology. 1995;195(1):65-72.

27. Barnes AS, Haker SJ, Mulkern RV, So M, D’Amico AV, Tempany CM. Magnetic resonance spectroscopy-guided transperineal prostate biopsy and brachytherapy for recurrent prostate cancer. Urology. 2005; 66(6): 1319.

28. De Stefano N, Matthews PM, Fu L, et al. Axonal damage correlates with disability in patients with relapsing-remitting multiple sclerosis. Results of a longitudinal magnetic resonance spectroscopy study. Brain. 1998;121(Pt 8):1469-1477.

29. Martin E, Capone A, Schneider J, Hennig J, Thiel T. Absence of $\mathrm{N}$-acetylaspartate in the human brain: impact on neurospectroscopy? Ann Neurol. 2001;49(4):518-521.

30. Harris RE, Napadow V, Huggins JP, et al. Pregabalin rectifies aberrant brain chemistry, connectivity, and functional response in chronic pain patients. Anesthesiology. 2013;119(6):1453-1464.

31. Deelchand DK, Iltis I, Henry PG. Improved quantification precision of human brain short echo-time ${ }^{1} \mathrm{H}$ magnetic resonance spectroscopy at high magnetic field: a simulation study. Magn Reson Med. 2014;72(1):20-25.
Journal of Pain Research

\section{Publish your work in this journal}

The Journal of Pain Research is an international, peer reviewed, open access, online journal that welcomes laboratory and clinical findings in the fields of pain research and the prevention and management of pain. Original research, reviews, symposium reports, hypothesis formation and commentaries are all considered for publication.

\section{Dovepress}

The manuscript management system is completely online and includes a very quick and fair peer-review system, which is all easy to use. Visit http://www.dovepress.com/testimonials.php to read real quotes from published authors. 